\title{
The DEA Game Cross-efficiency Model for Supplier Selection Problem under Competition
}

\author{
Ruimin Ma, Lifei Yao, Maozhu Jin* and Peiyu Ren \\ Buisness School, Sichuan University, Chengdu 610064, China
}

Received: 14 Apr. 2013, Revised: 15 Aug. 2013, Accepted: 17 Aug. 2013

Published online: 1 Mar. 2014

\begin{abstract}
As the most important responsibility of purchasing management, the problem of supplier evaluation and selection has always received a great deal of attention from practitioners and researchers. This management decision is a challenge due to the complexity and various criteria involved. Many methods based on data envelopment analysis(DEA) emerged, especially the cross efficiency. But it exists some limitations, such as the cross efficiency value is often non-unique, average cross efficiency measure is not good because it is not pareto solution. This paper considers the competition between the suppliers and presents game cross efficiency which is based on DEA to assess supplier performance. This method can get a unique efficiency and it is pareto solution. Numerical example is used to illustrate application and feasibility of the proposed methodology.
\end{abstract}

Keywords: Supplier selection; Competition; DEA; Game; Cross efficiency.

\section{Introduction}

Supply chain management(SCM) is a concept that originated and flourished in the manufacturing industry. The first visible signs of SCM were in the Just-In-Time (JIT) delivery system, as part of the Toyota Production System. This system aimed to regulate supplies to the Toyota motor factory just in the right-small-amount, just in the right time. The main goal of this system was to drastically decrease inventories, and to effectively regulate the suppliers' interaction with the production line. Another stimulus for SCM originated in the field of quality control. As early as 1950, in an address to Japanese industrial leaders, Deming[1] suggested that working with the supplier as a partner in a long-term relationship of loyalty and trust would improve the quality and decrease the costs of production.

As the world is becoming highly complex and specialized, the competition of SCM have been fierce. In order to gain competitive advantages in markets, manufacturers must collaborate, not only with component or raw material suppliers, but also with wholesalersdistributors, retailers, and customers, who all participate in a supply chain, directly or indirectly, in order to fulfill customer requests. SCM involves the management of transaction flows among players in a supply chain so as to maximize total supply chain profitability. SCM aims to minimize overall costs across the supply chain and to maximize the revenue generated from the customer in cooperation with business partners. Firms within a supply chain can achieve sustainable competitive advantages through developing much closer relationships with all companies, and they can significantly reduce time and costs depending on the appropriate management of the supply chain, while serving customer needs at the same time. In a competitive environment, successful SCM is much helpful in strengthening the competitive edge of firms.

In today's competitive environment, companies are trying to attain the goals of low cost, high quality, flexibility and more customer satisfaction. So they should know that for a company to remain competitive it is crucial to work with its supply chain partners. Supply chain supplier selection is one of the important operational decisions, involving not only selection of vendors, but other decisions with respect to quantities to order from each vendor. Globalization has led to the opportunities for many to utilize sources from around the world. This, of course, introduces additional decision-making considerations. Vendor selection

\footnotetext{
*Corresponding author e-mail: jinmaozhu@ scu.edu.cn
} 
decisions are complicated by the fact that various criteria must be considered in the decision-making process.

This paper, therefor, focuses on the selection of competitive suppliers in order to develop an efficient supply chain. The rest of the paper is organized as follows. Section 2 describes the supplier selection problem, and summarizes the existing methods. Section 3 introduces the data envelopment analysis(DEA), which considers the competition between the suppliers. Section 4 exhibits the results from the new method by using actual data. Finally, Section 5 concludes this paper.

\section{Literature review}

Over the years, several multi-criteria techniques have been proposed for the effective evaluation and selection of vendors. According to literature, some supplier selection criteria are found to vary in different situations, and experts agree that there is no one best way to evaluate, select suppliers and that organizations use a variety of different approaches in their evaluating processes.

Dickson [2] addressed research on supplier selection early, identified over 20 supplier attributes which managers trade off when choosing a supplier. The criteria may have quantitative as well as qualitative dimensions. While, Traditional vendor evaluation methods, however, mainly considered financial measures in the decision making process.

Weber, Current, and Ben-ton [3] derived key factors that were thought to affect supplier selection decisions. These were taken from 74 related articles which have appeared since Dickson's well-known study. Based on a comprehensive review of vendor evaluation methods, they summarized that price was the highest-ranked factor, followed by delivery and quality. After Weber's work, most researchers focused on supplier-selection criteria in either specific industries or specific countries $[4,5,6,7]$. Nassimbeni [8]surveyed 78 Italian enterprises concerning their international source, finding that quality and technological content were the highest ranked criteria for vendor selection, with cost ranked only fifth.

Some mathematical programming approaches had been used for supplier selection in the past. Such as, Weber and Current [9] proposed a multi-objective approach to supplier selection to aim at minimizing the price, maximizing the quality and on time delivery using systems' constraints and policy constraints in a mixed integer model. Ghodsypour and O'Brien [10] proposed an integration of AHP and linear programming to consider both tangible and intangible factors in choosing the best suppliers and placing the optimum order quantities among them such that the total value of purchasing becomes maximum. Karpak et al. [11] presented one of the "user-friendly" multiple criteria decision support systems-visual interactive goal programming (VIG). VIG facilitates the introduction of a decision support vehicle that helps improve the supplier selection decisions. çebi and Bayraktar [12] structured the supplier selection problem as an integrated lexico-graphic goal programming and AHP model including both quantitative and qualitative conflicting factors. Wang, Huang, and Wang [13] used AHP and preemptive goal programming based multi-criteria decision-making methodology is then developed to take into account both qualitative and quantitative factors in supplier selection. Azoulay-Schwartz [14] used Gittins indices to optimally select a supplier. To solve the vendor selection problem with multiple objectives, Kumar et al. [15] applied fuzzy goal programming approach. To incorporate the imprecise aspiration levels of the goals, they formulated a vendor selection problem as a fuzzy mixed integer goal programming that includes three primary goals: minimizing the net cost, minimizing the net rejections, and minimizing the net late deliveries subject to realistic constraints regarding buyer's demand, vendor's capacity, vendor's quota flexibility, purchasing value of items, budget allocation to individual vendor, etc. Wang and Yang [16] searched supplier selection in a quantity discount environment using multi objective linear programming, AHP, and fuzzy compromise programming.

\section{DEA Method for Supplier Selection}

In this section, we mainly summarize the studies which applies DEA method for supplier selection. Performance evaluation is an important task for supplier to find its weaknesses so that subsequent improvements can be made.

Data envelopment analysis (DEA) proposed by Charnes [17] (CCR model) and developed by Banker [18](BCC model), DEA method based on the marginal benefit theory and linear programming theory, through definite whether decision making units (DMUs) are located in production frontier to compare the relative efficiencies among DMUs and shows the respective optimum value, is an approach for measuring the relative efficiency of peer DMUs with multiple inputs and multiple outputs. DEA method has many outstanding advantages: such as, (1) Input and output indicators don't have to be unified dimension. (2) The weights of input and output are determined by solving the linear programming that avoid the effect of human's subjective determining the weight. (3) It does not need to consider the relation between the input and output etc. These advantages make DEA in nonprofit organizations and profit organizations are widely application, such as business firms, hospitals, cities, army Olympic games and many others, and application fields are expanding. In addition, DEA is also one of the most used techniques for supplier selection [19].

In recent years, the method of using DEA to sort DMUs emerge in endlessly. Weber [20] combined a multi-objective programming (MOP) and DEA method to 
provide buyers with a tool for negotiating with vendors that were not selected right away, as well as to evaluate potential suppliers. Ha [21] outlined a hybrid method, which incorporates multiple techniques like AHP, DEA and neural network(NN) into an evaluation process, in order to select competitive suppliers in a supply chain. They finally devised a combined supplier score for rating suppliers. Dilay [22] applied the integration method of DEA and neural network for evaluation of suppliers under incomplete information of evaluation criteria. Desheng $\mathrm{Wu}[23]$ presented a hybrid model using data envelopment analysis (DEA), decision trees (DT) and neural networks (NNs)to assess supplier performance. A hybrid methodology combining the data envelopment analytic hierarchy process (DEAHP) and activity-based costing (ABC) was developed for supplier evaluation by Zhang [24]. The advantages of the proposed approach include increasing suppliers' overall efficiency and also reducing indirect costs which are related to the quality of the supplier and to their delivery performance record.Parthiban [25] presented the integrated approach of multiple multi criteria decision making (MCDM) techniques such as fuzzy logic, strength-weakness-opportunity-threat (SWOT) analysis, and data envelopment analysis.

From the above studies we can see that, the DEA proposed by Charnes [17] is a pure self-evaluation model, which always combined with other method, like AHP, ANP, NN and others. Consequently, in order to increase the discriminatory power of DEA, cross efficiency extends DEA into a peer evaluation model, was proposed by Sexton [26] and improved by Doyle [27]. The cross-efficiency score of a DMU is obtained by computing that DMU's set of $n$ scores (using the $n$ sets of optimal weights), and then averaging those scores. Therefore, cross efficiency is a better choice for measuring the performance of the suppliers.

Recently, few scholars used cross-efficiency evaluation to measure the performance of the suppliers. Noorizadeh [28] proposed a cross-efficiency formulation of DEA, which can treat undesirable outputs to get a complete ranking among suppliers and also eliminate unrealistic weighting schemes among them. Mahdiloo [29] focused on the supplier selection problem when the suppliers offer volume discounts to encourage the purchase of large volumes and used the cross-efficiency method to discuss suppliers offer volume discounts. Noorizadeh [30] proposed a cross-efficiency model which is able to consider non-discretionary inputs.

Though, in the above studies some specific problems in the supplier selection problem have been solved. Suppliers are treated as DMUs and competition among the vendors is not considered. This is due to the vendor of DEA models used which only assume some basic relations among the inputs and outputs. As noted in [31], when DMUs are viewed as players in a game, cross-efficiency scores may be viewed as payoffs, and each DMU may choose to take a non-cooperative game stance to the extent that it will attempt to maximize its (worst possible) payoff. If one adopts this game theoretic approach, it may be argued that the existing approaches to cross evaluation suffer shortcomings in regard to these common situations. They proposed a DEA game cross-efficiency approach when competition exists among the DMUs and proved the approach yields a set of unique Nash equilibrium DEA weights.

\section{The DEA Game Cross-efficiency approach}

To introduce the method for supplier selection, Table 1 lists the nomenclature used to formulate the problem under consideration.

\begin{tabular}{l}
\hline Problem parameters \\
\hline$j=1,2, \cdots, n$ collection of suppliers(DMUs) \\
$r=1,2, \cdots, s$ the set of outputs \\
$i=1,2, \cdots, m$ the set of inputs \\
$y_{r j}=$ the $r$ th output of $j$ th DMU \\
$x_{i j}=$ the $i$ th input of $j$ th DMU \\
$u_{r}=$ weight of the $r$ th output \\
$v_{i}=$ weight of the $i$ th input
\end{tabular}

In the traditional DEA approach, the efficiency of supplier $j$ can be computed as follows:

$$
\begin{aligned}
& \operatorname{Max} \quad E_{d d}=\sum_{r=1}^{s} u_{r} y_{r d} \\
& \text { s.t }\left\{\begin{array}{l}
\sum_{i=1}^{m} v_{i} x_{i j}-\sum_{r=1}^{s} u_{r} y_{r j} \geq 0, j=1,2, \cdots, n, \\
\sum_{i=1}^{m} v_{i} x_{i d}=1 \\
v_{i} \geq 0, i=1,2, \cdots, m \\
u_{r} \geq 0, r=1,2, \cdots, s .
\end{array}\right.
\end{aligned}
$$

For each $D M U_{d}$ under evaluation, we can obtain a set of optimal weights by solving model $(M-1)$, $\left(v_{1 d}^{*}, v_{2 d}^{*}, \cdots, v_{m d}^{*}, u_{1 d}^{*}, u_{2 d}^{*}, \cdots, u_{s d}^{*}\right)$.

$M-1$ allows each DMU to choose the optimal weights combination, in order to maximize the efficiency value, thus it is difficult to achieve sufficient ranking. So cross efficiency method was proposed, it can not only provide a unique ordering of the DMUs, and eliminate unrealistic weight schemes without requiring the elicitation of weight restrictions from application area experts.

Using the set $\left(v_{1 d}^{*}, v_{2 d}^{*}, \cdots, v_{m d}^{*}, u_{1 d}^{*}, u_{2 d}^{*}, \cdots, u_{s d}^{*}\right)$, the $D M U_{d}$-based cross efficiency for any $\operatorname{DMU}_{j}(j=1,2, \cdots, n)$ is calculated as

$$
E_{d j}=\frac{\sum_{r=1}^{s} u_{r d}^{*} y_{r j}}{\sum_{i=1}^{m} v_{i d}^{*} x_{i j}}, d, j=1,2, \cdots, n
$$


For $D M U_{j}$, the average of all $E_{d j}$ can be used as a new cross-efficiency score measure for $D M U_{j}$,

$$
\overline{E_{j}}=\frac{1}{n} \sum_{d=1}^{n} E_{d j}, \quad d, j=1,2, \cdots, n .
$$

The strategy without adding any secondary target in the process of calculating cross efficiency is called Arbitrary strategy. It is noticed that model $(M-1)$ may have multiple optimal solutions. This non-uniqueness of input and output weights would damage the use of cross-efficiency evaluation if it were not resolved. To resolve this problem, Sexton [26] introduced a secondary goal to optimize the input and output weights. The most commonly used secondary goals were aggressive and benevolent formulations of cross-efficiency calculation introduced by Doyle [27].

Two kinds of different secondary goals represent two opposite strategies. In the case of unchanging the self-evaluation value $E_{d d}$, the benevolent model maximizes the cross-efficiencies of the other DMUs to some extent, which was formulated as follow:

$$
\begin{aligned}
& \operatorname{Max} \frac{1}{n-1} \sum_{j \neq d} \frac{\sum_{r=1}^{s} u_{r d} y_{r j}}{\sum_{i=1}^{m} v_{i d} x_{i j}} \\
& \text { s.t }\left\{\begin{array}{l}
\sum_{i=1}^{m} v_{i d} x_{i j}-\sum_{r=1}^{s} u_{r d} y_{r j} \geq 0, j=1,2, \cdots, n, \\
\sum_{i=1}^{m} v_{i d} x_{i d}=1, \\
\sum_{r=1}^{s} u_{r d} y_{r d}=E_{d d}, \\
v_{i d} \geq 0, i=1,2, \cdots, m, \\
u_{r d} \geq 0, r=1,2, \cdots, s .
\end{array}\right.
\end{aligned}
$$

Oppositely, the aggressive model aims to minimize the cross-efficiencies of the other DMUs in some way.

The traditional DEA model just considered to choose the optimal weights under the condition that all the DMUs' efficiency score are not greater than 1. For the cross-efficiency DEA model, the efficiency score of each DMU considered itself optimal weights and others'. But, in practical application, like supplier selection, DMUs can be looked upon as being in competition with one another, and as such each may argue that its multiplier bundle should be chosen with a view to how that bundle impacts the implied performance of the other DMUs (should that bundle be used to evaluate each of those others).

Liang [31] defined game cross-efficiency. In a game sense, one player $D M U^{d}$ is given an efficiency score $\alpha_{d}$, and that another player $D M U_{j}$ then tries to maximize its own efficiency, subject to the condition that $\alpha_{d}$ cannot be decreased. The game cross-efficiency for $D M U_{j}$ relative to $D M U_{d}$ formulated as,

$$
\alpha_{d j}=\frac{\sum_{r=1}^{s} u_{r j}^{d} y_{r j}}{\sum_{i=1}^{m} v_{i j}^{d} x_{i j}}, d=1,2, \cdots, n,
$$

For each $D M U_{j}$, the game d-cross efficiency can be calculated [15]:

$$
\begin{aligned}
& \operatorname{Max} \quad \sum_{r=1}^{s} u_{r j}^{d} y_{r j} \\
& \qquad . t\left\{\begin{array}{l}
\sum_{i=1}^{m} v_{i j}^{d} x_{i l}-\sum_{r=1}^{s} u_{r j}^{d} y_{r l} \geq 0, l=1,2, \cdots, n, \\
\sum_{i=1}^{m} v_{i j}^{d} x_{i j}=1, \\
\alpha_{d} \sum_{i=1}^{m} v_{i j}^{d} x_{i d}-\sum_{r=1}^{s} u_{r j}^{d} y_{r d} \leq 0, \\
v_{i j}^{d} \geq 0, i=1,2, \cdots, m, \\
u_{r j}^{d} \geq 0, r=1,2, \cdots, s .
\end{array}\right.
\end{aligned}
$$

Assumed the optimal solution of model $M-3$ as $u_{r j}^{d^{*}}\left(\alpha_{d}\right)$, for For each $D M U_{j}$, the average game cross-efficiency formulated as:

$$
\alpha_{j}=\frac{1}{n} \sum_{d=1}^{n} \sum_{r=1}^{s} u_{r j}^{d^{*}}\left(\alpha_{d}\right) y_{r j}
$$

\section{The Case Study}

\subsection{Data sources}

The data set for this example is partially taken from [32] contains specifications on 12 suppliers. The supplier inputs considered are Return rate, Discount rate, Operating expense rate. The outputs utilized in the study are Research and Development rate (R\&D rate), Productivity, Gross profit rate, Quantity discount, Inventory turnover ratio. The detail data is shown in table 1.

\subsection{Suppliers ranking}

In this section, we ranked the suppliers by multiple method, CCR, Aggressive, Arbitrary, Benevolent and Game DEA. Based on numerical data regarding the input and output items of each supplier listed in Table 1, the models $M-1, M-2, M-3$ are respectively applied to determine their relative efficiencies. The Game DEA cross efficiency are calculated through 3 steps, which was introduced detail by Liang [31]. In this paper, the cross efficiency of Arbitrary strategy sets as initial value of $\alpha_{d}$, $\varepsilon$ set as 0.0001 . The results are listed in Table 2 . 
Table 1 Parameter values of performance indicators for 12 suppliers

\begin{tabular}{ccccccccc}
\hline \multirow{2}{*}{$\begin{array}{c}\text { Suppliers } \\
\text { No.(DMU) }\end{array}$} & $\begin{array}{c}\text { Return } \\
\text { rate }\end{array}$ & $\begin{array}{c}\text { Discount } \\
\text { rate }\end{array}$ & $\begin{array}{c}\text { Operating } \\
\text { expense } \\
\text { rate }\end{array}$ & $\begin{array}{c}\text { R\&D } \\
\text { rate }\end{array}$ & $\begin{array}{c}\text { Product- } \\
\text { ivity }\end{array}$ & $\begin{array}{c}\text { Gross } \\
\text { profit } \\
\text { rate }\end{array}$ & $\begin{array}{c}\text { Quantity } \\
\text { discount } \\
(\%)\end{array}$ & $\begin{array}{c}\text { Inventory } \\
\text { turnover } \\
\text { ratio }\end{array}$ \\
\hline 1 & 0.06 & 0.66 & 5.73 & 1.11 & 201 & 0.01 & 7 & 0.67 \\
2 & 0.54 & 0.22 & 2.92 & 1.13 & 267 & 9.69 & 7 & 6.02 \\
3 & 1.11 & 0.5 & 8.38 & 2.12 & 311 & 6.36 & 5 & 5.8 \\
4 & 0.15 & 0.48 & 5.68 & 1.57 & 361 & 6.42 & 5 & 6.17 \\
5 & 0.19 & 0.41 & 4.16 & 1.5 & 300 & 9.51 & 10 & 6.76 \\
6 & 1.28 & 0.5 & 7.01 & 3.08 & 310 & 13.81 & 7 & 7.48 \\
7 & 0.01 & 0.01 & 5 & 2 & 250 & 5.41 & 8 & 7.04 \\
8 & 0.42 & 0.13 & 2.82 & 1.04 & 398 & 6.82 & 7 & 11.16 \\
9 & 0.65 & 1.05 & 3.83 & 1.66 & 375 & 7.51 & 5 & 5.17 \\
10 & 0.25 & 0.07 & 2.64 & 2.62 & 103 & 1.43 & 8 & 5.16 \\
11 & 0.72 & 0.18 & 4.25 & 2.09 & 164 & 6.71 & 6 & 12.45 \\
12 & 0.13 & 1.37 & 5.55 & 2.52 & 200 & 2.98 & 6 & 6.36 \\
\hline
\end{tabular}

Table 2 CCR efficiency, DEA cross efficiency, Game cross efficiency

\begin{tabular}{cccccc}
\hline \multirow{2}{*}{ Suppliers (DMUs) } & \multirow{2}{*}{ CCR } & \multicolumn{3}{c}{ cross efficiency } & Game cross efficjency \\
\cline { 3 - 4 } & & Aggressive & Arbitrary & Benevolent & 0.6271 \\
2 & 0.6957 & 0.5345 & 0.3307 & 0.5458 & 0.9867 \\
3 & 1.0000 & 0.3834 & 0.6966 & 0.7385 & 0.4091 \\
4 & 0.4104 & 0.7880 & 0.3068 & 0.7543 & 0.9179 \\
5 & 0.9757 & 0.5914 & 0.6593 & 0.6125 & 0.9441 \\
6 & 1.0000 & 0.3850 & 0.8377 & 0.7256 & 0.7443 \\
7 & 0.7824 & 0.6562 & 0.4866 & 0.6562 & 0.9799 \\
8 & 1.0000 & 0.0230 & 0.8304 & 0.7365 & 0.9523 \\
9 & 1.0000 & 0.3043 & 0.8265 & 0.7880 & 0.8438 \\
10 & 0.8784 & 0.6921 & 0.6106 & 0.6831 & 1.0000 \\
11 & 1.0000 & 0.2295 & 0.7697 & 0.7344 & 0.8052 \\
12 & 0.8769 & 0.5500 & 0.5280 & 0.5632 & 0.7947 \\
\hline
\end{tabular}

Table 3 Comparison of ranks by different strategies for supplier selection

\begin{tabular}{cccccc}
\hline \multirow{2}{*}{ Suppliers (DMUs) } & \multirow{2}{*}{ CCR } & \multicolumn{3}{c}{ cross efficiency } & \multirow{2}{*}{ Game cross efficiency } \\
\cline { 3 - 5 } & & Aggressive & Arbitrary & Benevolent & 11 \\
2 & 11 & 6 & 11 & 11 & 2 \\
3 & 12 & 9 & 5 & 3 & 12 \\
4 & 8 & 1 & 12 & 2 & 6 \\
5 & 6 & 4 & 6 & 9 & 5 \\
6 & 1 & 8 & 1 & 6 & 10 \\
7 & 10 & 3 & 10 & 8 & 3 \\
8 & 1 & 12 & 2 & 4 & 7 \\
9 & 1 & 10 & 3 & 1 & 1 \\
10 & 7 & 2 & 7 & 7 & 8 \\
11 & 1 & 11 & 4 & 5 & 9 \\
12 & 8 & 5 & 9 & 10 &
\end{tabular}

According to the efficiency of all kinds of strategies, we provide the ranks of the suppliers, which are shown in table 3.

As seen from the results in Table 2 and Table 3, The game DEA can rank all the suppliers, it is not as the results in [32], which divided the suppliers to two parties: efficient and inefficient, then rank the efficient DMUs. The ranking result of Game DEA is different from other strategies, in practical application, there must be competition between the suppliers, so using game DEA to rank the suppliers is more reasonable.

\subsection{Convergence procedure of game cross efficiency}




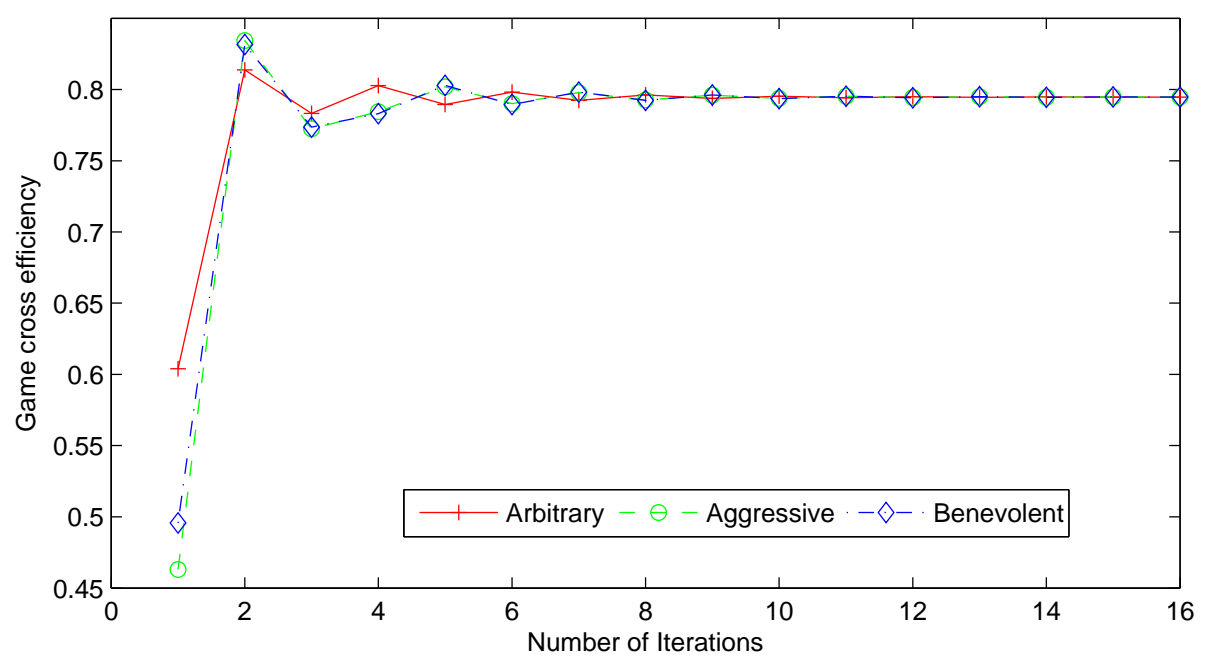

Fig. 1: Convergence procedure of game cross efficiency for 3 strategies

In this section, we show the Convergence procedure of game cross efficiency, which respectively uses the efficiency value from aggressive strategy, arbitrary strategy and benevolent strategy. The DMU 12 is selected, $(\varepsilon=0.0001)$ and the result shows in Fig 1. The Fig 2 show the Convergence procedure of game cross efficiency for all the DMUs.

From the Fig 1 we can see, the cross efficiency value of three different strategies ultimately all converge to the same game cross efficiency value, this indicates that the solution is a Nash equilibrium, which have proved by [31]. The Fig 2 shows that, after 12 iterations, all of the DMUs calculated by the proposed algorithm achieves the steady game cross efficiency value. Moreover, from Fig.2 we notice that when the number of iterations is an odd number, the game cross efficiency will increase; while the number of iterations is an even number, the game cross efficiency will decrease, until the efficiency achieves a stable value.

\section{Conclusion}

In most cases, a DMU can be regarded as being in direct or indirect competition environment, not only traditional DEA evaluation method for the self-assessment but also cross efficiency evaluation methods for peer evaluation are not very good to be applied in the competitive environment, more important is that the traditional DEA method in the optimization process could be exist multiple optimal solution, different optimal solutions may make the difference the DMUs' cross efficiency is very big, so the cross efficiency method seems to be random and unstable. In this paper, we use game cross efficiency method to evaluation the DMUs, this method takes the competition between the suppliers into consideration which is more reasonable. Through the case study, we find that the results of game cross efficiency is different from all other method, and provide a new direction for supplier selection.
To provide some further insights, it is notable that the models developed in this paper are certain, but, practically some parameters are uncertain, stochastic DEA and fuzzy DEA may be extended into the models. In addition, Confidence regions restrictions also can be taken into consideration.

\section{Acknowledgement}

This work was supported by Major International Joint Research Program of the National Natural Science Foundation of China (71020107027), National High Technology Research and Development Major Program of China (Program 863) (2008AA04A107), Central University Fund of Sichuan Unversity No. skqy201112.

\section{References}

[1] W. E. Deming, Massachusetts Institute of Technology, Cambridge, (1982).

[2] G. W. Dickson, Journal of Purchasing, 2, (1966).

[3] C. A. J. R. Weber, Current and W. C. Benton, European Journal of Operational Research, 50, (1991).

[4] A. Segev, J. Gebauer and C. Beam, CMIT working paper WP-98-1033, University of California, Berkeley, (1998).

[5] H. Min and W. P. Galle, International Journal of Operations \& Production Management, 19, (1999).

[6] N. Stavropolous, Telecommunications Journal of Australia, 50, (2000)

[7] M. Sonmez, Business school papers series, Loughborough University, 1, (2006).

[8] G. Nassimbeni, International Journal of Production Economics, 103, (2006).

[9] C. A. Weber, and J. R. Current, European Journal of Operational Research, 68, (1993). 


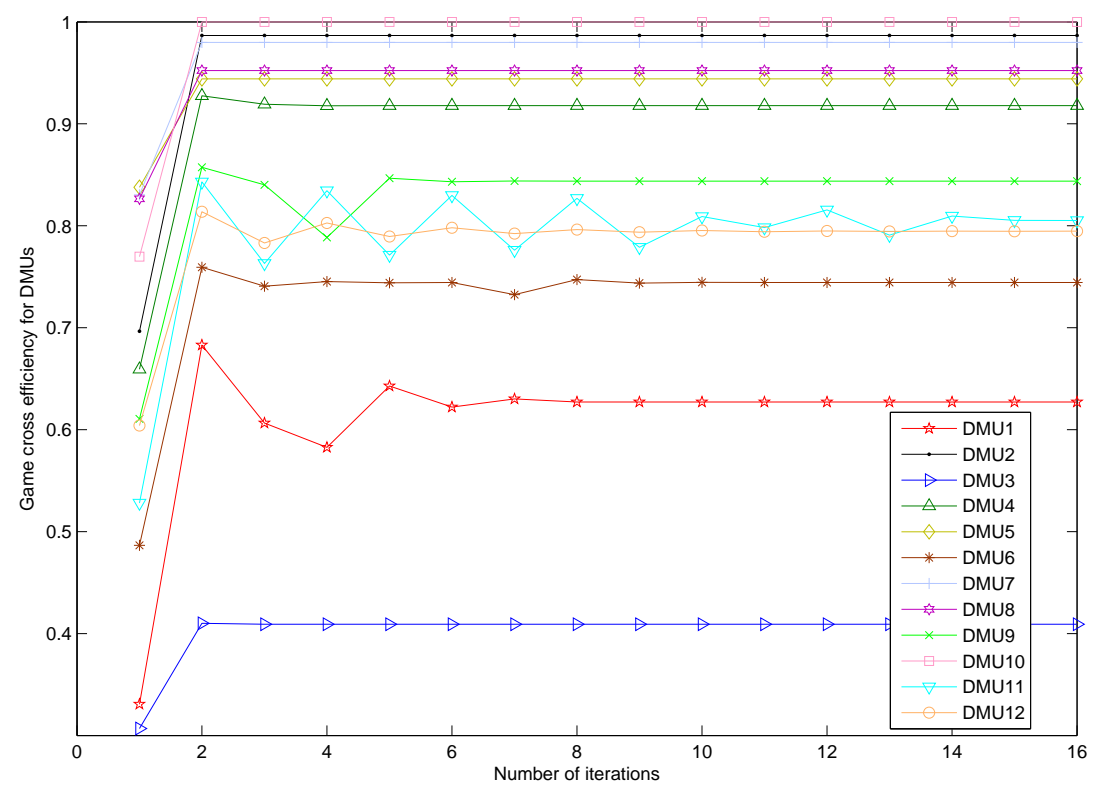

Fig. 2: Convergence procedure of game cross efficiency for DMUs

[10] S. H. Ghodsypour and C. O’Brien, International Journal of Production Economics, 56, (1998).

[11] B. Karpak, E. Kumcu and R. R. Kasuganti, European Journal of Purchasing \& Supply Management, 7, (2001).

[12] F. çebi and D. Bayraktar, Logistics Information Management, 16, (2003).

[13] G. Wang, S. H. Huang and J. P. Dismukes, International Journal of Production Economics, 91, (2004).

[14] R. Azoulay-Schwartz, S. Kraus and J. Wilkenfeld, Decision Support Systems, 38, (2004).

[15] M. Kumar, P. Vrat and R. Shankar, Computers and Industrial Engineering, 46, (2004).

[16] T. Y. Wang and Y. H. Yang, Expert Systems with Applications, 36, (2009).

[17] A. Charnes, W. W. Cooper and E. Rhodes, European Journal of Operational Research, 2, (1978).

[18] R. D. Banker, A. Charnes, and W. W. Cooper, Management Science, 30, (1984).

[19] William Ho , Xiaowei Xu and Prasanta K. Dey, European Journal of Operational Research, 8, (2010).

[20] C. A. Weber, J. R. Current and A. Desai, Supply Chain Management: an International Journal, 5, (2000).

[21] Sung Ho Ha and Ramayya Krishnan, Expert Systems with Applications, 34, (2008).

[22] Dilay Çelebi and Demet Bayraktar, Expert Systems with Applications, 35, (2008).

[23] Desheng Wu, Expert Systems with Applications, 36, (2009).

[24] X. J. Zhang and C. K. M. Lee and S. Chena, International Journal of Production Research, 50, (2012).

[25] P. Parthiban, HA. Zubar, and P. Katakar, International Journal of Production Research, 51, (2013).
[26] T. R. Sexton, R. H. Silkman and A. J. Hogan, Measuring efficiency: an assessment of data envelopment analysis, 32, (1986).

[27] J. Doyle and R. Green, Journal of the Operational Research Society, 45, (1994).

[28] A. Noorizadeh, M. Mahdiloo and R. F. Saen, International Journal of Logistics Systems and Management, 11, (2012).

[29] M. Mahdiloo, A. Noorizadeh and R. F. Saen, International Journal of Services and Operations Management, 11, (2012).

[30] A. Noorizadeh, M. Mahdiloo and R. F. Saen, International Journal of Shipping and Transport Logistics, 5, (2001).

[31] L. Liang, J. Wu, W. D. Cook and J. Zhu, Operations Reaearch, 56, (2008).

[32] Yuh Jen Chen, Information Sciences, 181, (2011). 


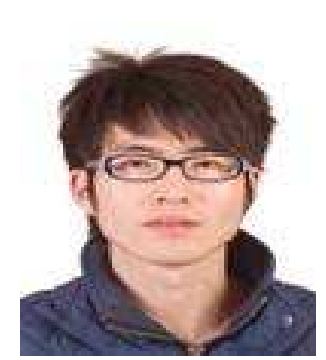

Ruimin Ma is a doctoral student in Sichuan University for majoring in management science and engineering, and a member of Information and Business Management Institute of Sichuan University. His researches mainly relate to simulation, multi-objective decision, and vehicle scheduling, etc.

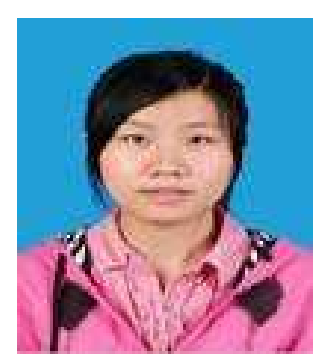

Lifei Yao is a Graduate student in Sichuan University for majoring in management science and engineering, and a member of Information and Business Management Institute of Sichuan University. Her research interests are prediction, evaluation, decision control and vehicle scheduling.

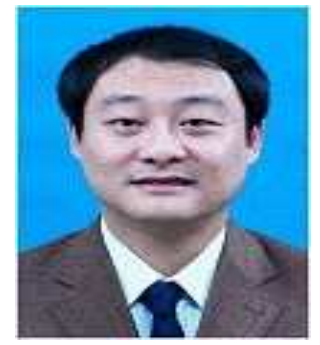

Maozhu Jin is an instructor of Business School,the tutor of MBA operations management and innovation and entrepreneurship management in Sichuan University. He has been engaged in the teaching of core curriculums such as operations management and management consulting. His current research interests include the areas of operations management, organizational process reengineering, strategic management, service operations management, platform-based mass customization and risk management. He has published two books and over ten research papers in authoritative journals of high quality both at home and abroad, and ten of them are retrieved by SCI and EI.

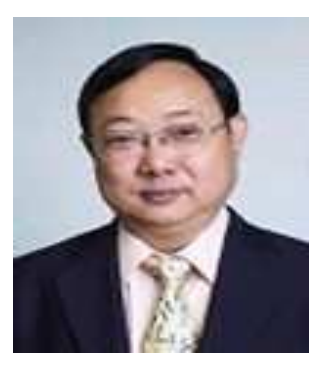

Peiyu Ren is a Professor, $\mathrm{PhD}$ Supervisor, currently acting as the Director of Information and Business Management Research Institute of Sichuan University. He has presided over and completed five surface projects of National Natural Science Foundation of China, being in charge of project research of Projects 863, 985 and 211, having published 15 books, monographs and more than 100 academic papers, including SCI, EI and CSSCI. 